\title{
Analysis of Reflectance and Transmittance Characteristics of Optical Thin Film for Various Film Materials, Thicknesses and Substrates
}

\author{
Md. Sultan $\mathrm{Z}^{1 *}$ and Sultana $\mathrm{N}^{2}$
}

${ }^{1}$ Department of Electrical and Electronic Engineering, Hajee Mohammad Danesh Science and Technology University, Bangladesh

${ }^{2}$ Department of Telecommunication and Electronic Engineering, Hajee Mohammad Danesh Science and Technology University, Bangladesh

\begin{abstract}
Optical thin film can control the reflection, refraction and transmission of specific wavelength of electromagnetic radiation and have numerous applications such as reflector, anti-reflector, attenuator, photovoltaic cell and refractor in the electromagnetic radiation spectrum. To perform the particular function for which they are designed, precise control of various film parameters such as thickness, composition, roughness, uniformity is necessary. Silicon dioxide, Zinc oxide, Zinc telluride are the most promising materials in optoelectronic and optical applications in the visible region as well as in the infrared and UV region. In this research, the optical properties such as spectral reflectance and transmittance of nano-scale optical thin films have been studied and analyzed for those materials on different substrates to obtain the optimal configuration for the best performance. To obtain this, the equations of reflectance and transmittance for thin film have been derived, then simulated and visualized by Matlab code. By changing film materials, substrates and film thickness, transmittance and reflectance characteristics have been observed and analyzed. The result showed that the reflectance and transmittance characteristics of optical thin film are strongly dependent on the wavelength of electromagnetic spectra. The film and substrate materials are very effective on the reflectance and transmittance characteristics of the optical thin films. It is also found that the reflectance and transmittance characteristics are greatly affected by film thickness. This research work will benefit and enhance the value of nano coating technology to determine the best thin film/substrate configuration in the development of micro- and nano optoelectronic devices.
\end{abstract}

Keywords: Optical thin film; Reflectance; Transmittance; Antireflector; Matlab

\section{Introduction}

Optical thin-film having any desired reflectance and transmittance characteristics may be produced by depositing very thin layer of material on the surface of another material [1]. Significant research efforts have been made in recent years for developing optical thin films because of their potential applications in the field of electronics, optoelectronics, information technology as well as micro-nanotechnology. To perform the functions for which they are designed, thin films must have the proper thickness, composition, roughness, and other characteristics important to the particular application [2,3]. That's why it is important to know the thickness, optical constants, optical and absorption properties as a function of wavelength to predict the photoelectric behavior of modern optoelectronic and optical devices [4]. The structure of a thin film is manifested in the optical properties [5]. Optical property measurements and analysis tool determines spectral reflectance-transmittance characteristics of optical thin-film over wavelength range of ultraviolet (UV) to infrared (IR) regions [6]. By using this valuable tool, the desired amplitude and periodicity of reflectance and transmittance can be obtained by adjusting film's material, thickness, optical constant and other parameters related to film material and substrate. As a result the optimized film structure for particular application is obtained. The influence of film's materials, thickness and the substrate on the optical properties of the optical thin film is so high that an extensive study and analysis is still a necessary research issue to understand, control, optimize and develop them for particular application.

The purpose of this research is to analyze the reflectancetransmittance characteristics of multi-layer thin films for various film materials, substrates and thickness in order to improve the performance of existing thin film as well as to fabricate new optical thin film with excellent properties.
Silicon dioxide $\left(\mathrm{SiO}_{2}\right)$ is so important semiconductor material that the thin films of this semiconductor are broadly used in various fields such as passivation layers of electronic devices, protection layers of magnetic or optical disks and anti-reflective coatings of displays. There is still research scope to improve the performance of existing $\mathrm{SiO}_{2}$ thin film $[7,8]$. Due to unique optical, electrical and semiconducting properties, Zinc oxide $(\mathrm{ZnO})$ is a promising material suitable for electronic or optoelectronic applications such as solar cells, gas sensors, liquid crystal displays, integrated optics heat mirrors, surface acoustic wave devices etc. Despite several approaches adopted for making these $\mathrm{ZnO}$ thin films; the films still attract much research interest for controlling the size, shape, thickness, various parameters and quality of material that affect the optical and electronic characteristics of film $[9,10]$. Zinc telluride (ZnTe) is so attractive material in the field of microelectronics and optoelectronics that many researchers have been extensively studying the structural, optical and electrical properties of $\mathrm{ZnTe}$ thin films to improve the properties of the $\mathrm{ZnTe}$ films. Two crystalline insulators such as sapphire $\left(\mathrm{Al}_{2} \mathrm{O}_{3}\right)$ and rutile $\left(\mathrm{TiO}_{2}\right)$ have been used as substrates in this research. Normal incidence is considered (angle of incidence is zero) so that extinction coefficient of material becomes zero and there exist refractive index $n$ only. These materials do not absorb light itself in the visible, IR and UV ranges. In this research,

${ }^{*}$ Corresponding author: Md. Sultan Z, Department of Electrical and Electronic Engineering, Hajee Mohammad Danesh Science and Technology University, Dinajpur, Bangladesh, Tel: +880-531-61355; E-mail: mdzamilsultan@hstu.ac.bd

Received August 13, 2015; Accepted September 21, 2015; Published October 25, 2015

Citation: Sultan Z, Sultana N (2015) Analysis of Reflectance and Transmittance Characteristics of Optical Thin Film for Various Film Materials, Thicknesses and Substrates. J Electr Electron Syst 4: 160. doi:10.4172/2332-0796.1000160

Copyright: ( 2015 Sultan Z, et al. This is an open-access article distributed under the terms of the Creative Commons Attribution License, which permits unrestricted use, distribution, and reproduction in any medium, provided the original author and source are credited. 
the reflectance-transmittance characteristics of optical thin-film have been analyzed, visualized and compared for these three novel film materials $\mathrm{SiO}_{2}, \mathrm{ZnO}, \mathrm{ZnTe}$ and two substrates $\mathrm{Al}_{2} \mathrm{O}_{3}$ and $\mathrm{TiO}_{2}$.

The paper describes the analysis and simulation on reflectance and transmittance of optical thin-film.

\section{Theoretical Analysis and Simulation}

Whenever electromagnetic wave such as light crosses the interface between two different materials, the fraction of light is reflected by the inner surface while some amount of electromagnetic wave is refracted through the inner surface and finally transmitted. The reflectance is the amount of reflection in terms of energy while transmittance is the amount of transmission in terms of energy. In this section, the total amount of reflectance and transmittance of optical thin-film shown in Figure 1 have been calculated by theoretical analysis and then simulated by Matlab.

The total amount of reflectance of the film has been derived as

$$
R_{e f f}=\frac{P^{2}+Q^{2}+2 P Q \cos R}{1+P^{2} Q^{2}+2 P Q \cos R}
$$

The total amount of transmittance of the film has been derived as

$$
T_{e f f}=\frac{16 n_{0}^{2} n_{f}^{2} n_{s}}{1+P^{2} Q^{2}+2 P Q \cos R}
$$

where $P=\frac{n_{0}-n_{f}}{n_{0}+n_{f}}, \quad Q=\frac{n_{f}-n_{s}}{n_{f}+n_{s}}, \quad R=\frac{4 \pi}{\lambda} n_{f} d_{f} \quad$ and $n_{0}, n_{f}, n_{s}$ are the refractive indices of surrounding medium (air), film, substrate respectively, $d_{f}$ represents the film thickness and $\lambda$ is the wavelength of electromagnetic spectrum.

The equations (1) and (2) have been simulated by Matlab to visualize and investigate transmittance and reflectance properties of optical thin-film for novel film materials $\mathrm{SiO}_{2} \mathrm{ZnO}$ and $\mathrm{ZnTe}$ on two substrates $\mathrm{Al}_{2} \mathrm{O}_{3}$ and $\mathrm{TiO}_{2}$.

\section{Results and Discussions}

The reflectance $\left(\mathrm{R}_{\text {eff }}\right)$ and transmittance $\left(\mathrm{T}_{\text {eff }}\right)$ characteristics of optical thin film are visualized in Figures 2 and 3 as a function of wavelength for $\mathrm{SiO}_{2}$ coating, $\mathrm{ZnO}$ coating and $\mathrm{ZnTe}$ coating. It is found that the magnitude of reflectance and transmittance of optical thin film vary periodically with wavelengths. Multiple oscillations occur on the reflectance and transmittance curves due to interferences among multiple reflected waves. As the wavelength increases, oscillation

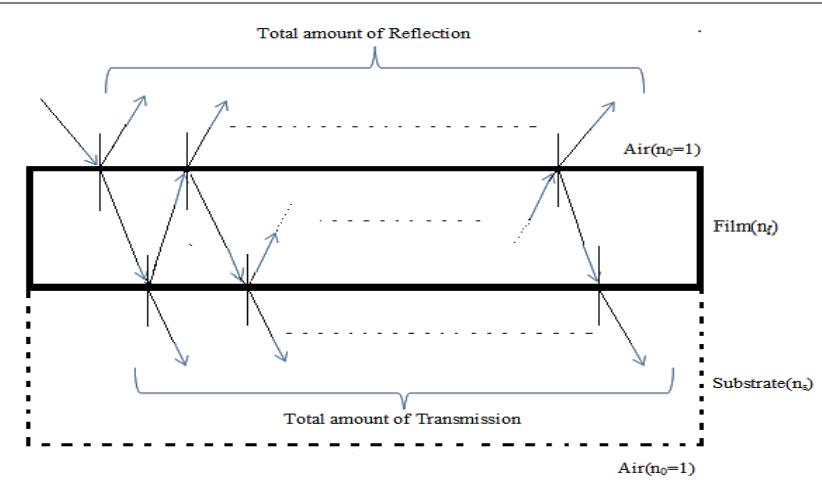

Figure 1: Reflection and transmission of light ray in optical thin-film. (a)
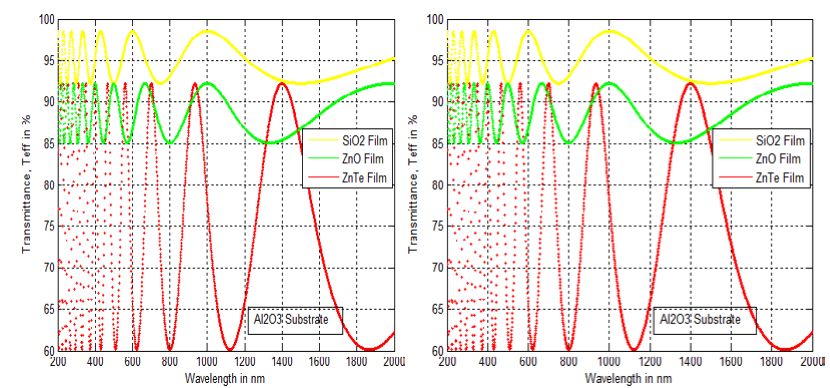

Figure 2: Reflectance and Transmittance for film materials $\mathrm{SiO}_{2}, \mathrm{ZnO}$ and $\mathrm{ZnTe}$ on $\mathrm{Al}_{2} \mathrm{O}_{3}$ substrate

(a)
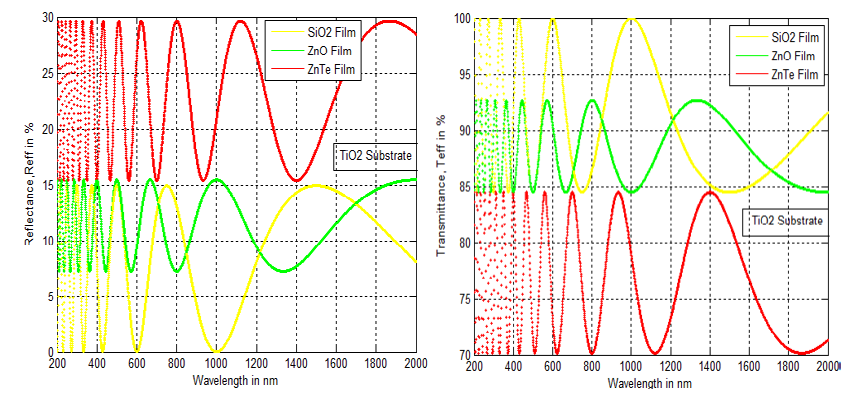

Figure 3: Reflectance and Transmittance for film materials $\mathrm{SiO}_{2}, \mathrm{ZnO}$ and $\mathrm{ZnTe}$ on $\mathrm{TiO}_{2}$ substrate.

period of these characteristics changes/increases. Thus the reflectance and transmittance characteristics of multilayer thin film are strongly dependent on the wavelength of electromagnetic spectra.

The effects of various film (coating) materials on the reflectance characteristics have been investigated by evaluating the reflectance curves of $\mathrm{SiO}_{2}$ coating, $\mathrm{ZnO}$ coating and $\mathrm{ZnTe}$ coating in Figure 2a. Similarly the effects of film materials on the transmittance features have been explored by comparing the transmittance curves in Figure $2 \mathrm{~b}$. The amplitude and periodicity of reflectance and transmittance are seriously changed with the film materials $\mathrm{SiO}_{2}, \mathrm{ZnO}$ and $\mathrm{ZnTe}$. It is found in Figure 2a that the maximum value of reflectance of $\mathrm{SiO}_{2}$ coating, $\mathrm{ZnO}$ coating and $\mathrm{ZnTe}$ coating happening at some wavelengths are $7.5 \%, 15 \%$ and $38 \%$ respectively while minimum reflectance of these coatings are $2 \%, 8 \%$ and $7.5 \%$ respectively. Similarly the highest values of transmittance of $\mathrm{SiO}_{2}$ coating, $\mathrm{ZnO}$ coating and $\mathrm{ZnTe}$ coating occurring at a number of wavelengths are $98 \%, 92.5 \%$ and $92.5 \%$ respectively whereas the lowest values of transmittance are $92.5 \%, 85 \%$ and $60 \%$ respectively. Some important points have been noticed that the percentage reflectance of $\mathrm{SiO}_{2}$ coating is the lowest among that of the three film materials because of the highest transmittance of $\mathrm{SiO}_{2}$. The percentage reflectance of $\mathrm{ZnTe}$ is the uppermost while percentage transmittance is the bottommost among the three film materials. The deviation of maximum to minimum $\mathrm{T}_{\text {eff }}$ and $\mathrm{R}_{\text {eff }}$ of $\mathrm{ZnTe}$ are importantly larger than that of $\mathrm{SiO}_{2}$ coating and $\mathrm{ZnO}$ coating. Thus the reflectance and transmittance characteristics of optical thin film are significantly influenced and affected by film (coating) materials. By choosing appropriate film material, the desired $\mathrm{R}_{\text {eff }}$ and $\mathrm{T}_{\text {eff }}$ characteristics of thin film can be obtained. 


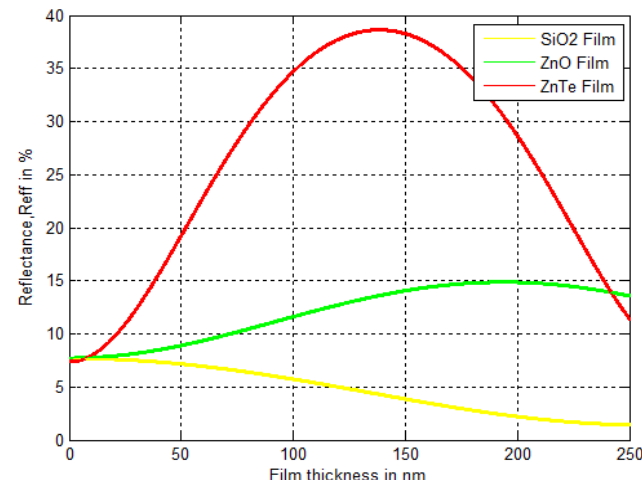

(a)

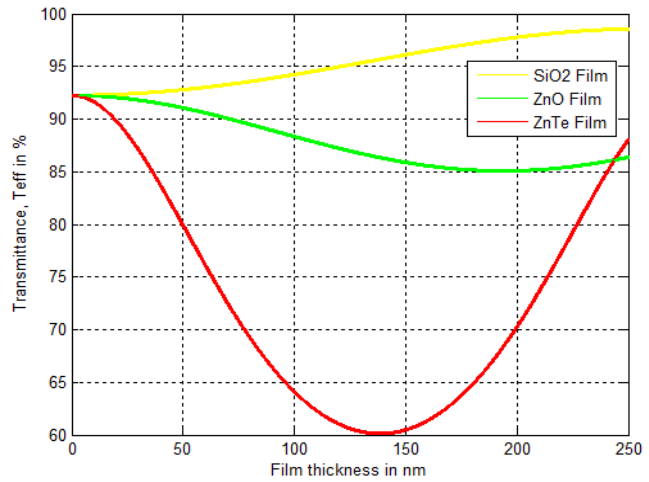

(b)

Figure 4: Reflectance and Transmittance as a function of film thickness.

The effects of substrate materials on the reflectance properties have been examined by comparing Figures $2 \mathrm{a}$ and $3 \mathrm{a}$. Furthermore, the effects of substrate materials on the transmittance properties have been estimated by associating Figure $2 \mathrm{~b}$ with Figure $3 \mathrm{~b}$. It is found from the comparison that the amplitude and periodicity of the reflectance and transmittance are strongly affected by substrates. In addition, the amount of the change due to substrate is very interesting and contrasting in $\mathrm{SiO}_{2}, \mathrm{ZnO}$ and $\mathrm{ZnTe}$ materials. As the substrate $\mathrm{Al}_{2} \mathrm{O}_{3}$ is changed to $\mathrm{TiO}_{2}$, the highest value of $\mathrm{R}_{\text {eff }}$ increased from $7.5 \%$ to $15 \%$ while the lowest value declined from $2 \%$ to $0 \%$ in case of $\mathrm{SiO}_{2}$ coating. The oscillation period is also changed. Zero reflectance has been obtained at some wavelengths in $\mathrm{SiO}_{2}$ coating on $\mathrm{TiO}_{2}$ substrate so that it can be used as good anti-reflector film. The change in reflectance-transmittance in $\mathrm{ZnTe}$ coating is quite dissimilar to that in $\mathrm{SiO}_{2}$ coating. In $\mathrm{ZnTe}$ coating, the maximum value of $\mathrm{R}_{\text {eff }}$ is dropped from $38 \%$ to $30 \%$ and minimum values is raised from $7.5 \%$ to $15.5 \%$ for changing substrates $\mathrm{Al}_{2} \mathrm{O}_{3}$ to $\mathrm{TiO}_{2}$. Slightly variation on $\mathrm{R}_{\text {eff }}$ and $\mathrm{T}_{\text {eff }}$ has been observed in $\mathrm{ZnO}$ coating for these two substrates. Thus it is concluded that the effects of substrate on the reflectance-transmittance characteristics are significantly different in various film materials. The optimized $\mathrm{R}_{\text {eff }}$ and $\mathrm{T}_{\text {eff }}$ characteristics of optical thin film can be gained by selecting suitable substrate material.

The $\mathrm{R}_{\text {eff }}$ and $\mathrm{T}_{\text {eff }}$ properties of nano scale optical thin film are shown in Figure 4 when thickness of film changed from 0 to $250 \mathrm{~nm}$.

It was observed from Figures $4 \mathrm{a}$ and $4 \mathrm{~b}$ that in case of $\mathrm{SiO}_{2}$ thin film on substrate $\mathrm{Al}_{2} \mathrm{O}_{3}$, increase of thickness causes decrease of $\mathrm{R}_{\text {eff }}$ and increase of $\mathrm{T}_{\text {eff }}$. Statistically, $\mathrm{R}_{\text {eff }}$ of $\mathrm{SiO}_{2}$ is smoothly decayed from $7.5 \%$ to $2 \%$ while $\mathrm{T}_{\text {eff }}$ is raised from $92.5 \%$ to $98 \%$ by increasing layer thickness from $0 \mathrm{~nm}$ to $250 \mathrm{~nm}$. Meanwhile in case of $\mathrm{ZnO}$ and $\mathrm{ZnTe}$ thin film on substrate $\mathrm{Al}_{2} \mathrm{O}_{3}$, increase of thickness up to certain value causes increase of $\mathrm{R}_{\text {eff }}$ and decrease of $\mathrm{T}_{\text {eff }}$. After the certain value, $\mathrm{R}_{\text {eff }}$ starts decreasing while $\mathrm{T}_{\text {eff }}$ increasing by increasing the film thickness. For $\mathrm{ZnO}$ film coating, $\mathrm{R}_{\text {eff }}$ is increased from $7.5 \%$ to $15 \%$ and $\mathrm{T}_{\text {eff }}$ is decreased from $92.5 \%$ to $85 \%$ by increasing layer thickness from 0 $\mathrm{nm}$ to $180 \mathrm{~nm}$. Further increasing thickness from $181 \mathrm{~nm}$ to $250 \mathrm{~nm}$ causes decline in the $\mathrm{R}_{\text {eff }}$ from $15 \%$ to $13 \%$ and rise in the $\mathrm{T}_{\text {eff }}$ from $85 \%$ to $87 \%$. $\mathrm{R}_{\text {eff }}$ of $\mathrm{ZnTe}$ is dramatically increased from $7.5 \%$ to $38 \%$ and $\mathrm{T}_{\text {eff }}$ is dramatically decreased from $92.5 \%$ to $60 \%$ by increasing film thickness from $0 \mathrm{~nm}$ to $140 \mathrm{~nm}$. Further increasing thickness from 141 $\mathrm{nm}$ to $250 \mathrm{~nm}$ causes serious decrease in the $\mathrm{R}_{\text {eff }}$ from $38 \%$ to $12 \%$ and serious increase in the $\mathrm{T}_{\text {eff }}$ from $60 \%$ to $88 \%$. Thus the reflectance and transmittance characteristics of optical thin film are greatly affected by film thickness. Also the amount of thickness effect on the reflectancetransmittance characteristics is significantly different in different film materials.

\section{Conclusion}

The reflectance and transmittance characteristics of the optical thin film have been visualized and analyzed for various film materials, substrates and film thickness. To do this, mathematical analyses have been done to obtain the equations of reflectance and transmittance. Then the two equations were simulated and visualized by Matlab program. After visualizing, the results showed that reflectance and transmittance of the optical thin film are strongly dependent on the electromagnetic wavelength. The amplitude and periodicity of oscillation of these characteristics vary with wavelength. It is found from the research that the effect of film materials and substrates materials are very effective on the reflectance and transmittance characteristics of the optical thin film. It is also found that the reflectance and transmittance characteristics are greatly affected by film thickness of the optical thin film. Industrial requirements are supported by selecting coating's materials, substrates and film thickness.

\section{References}

1. Wyant JC. Optics 505, Multilayer Films.nb

2. (2006) Advanced thin-film measurement systems, Thin-film measurement Filmetrices, Inc, 9335 Chesapeake Drive, San Diego, CA 92123.

3. Fukkao N, Kyung K, Shiratori S (2011) Automatic spray-LBL machine based on in-Situ QCM monitoring, ACS Publication, Macromolecules 44: 2964-2969.

4. Khelladi NB, Chabane NE (2013) Simulation study of optical transmission properties of $\mathrm{ZnO}$ thin film deposited on different substrates, American Journal of Optics and Photonics 1: 1-5.

5. Mullerova J, Jurecka S, Sutta P (2006) Optical characterization of polysilicon thin films for solar applications, ELSEVIER, Solar Energy.

6. Oloomi SAA, Saboonchi A, Sedaghat A (2010) Effects of thin film thickness on emittance, reflectance and transmittance of nano scale multilayers, Int J Physical Sci 5: 465-469.

7. Ranjgar A, Norouzi R, Zolanvari A, Sadeghi H (2013) Characterization and Optical Absorption Properties of Plasmonic Nanostructured Thin Films, Armenian Journal of Physics 6: 198-203.

8. Lamminpää A, Nevas S, Manoocheri F, Ikonen E (2006) Characterization of 
Citation: Sultan Z, Sultana N (2015) Analysis of Reflectance and Transmittance Characteristics of Optical Thin Film for Various Film Materials, Thicknesses and Substrates. J Electr Electron Syst 4: 160. doi:10.4172/2332-0796.1000160

Page 4 of 4

thin films based on reflectance and transmittance measurements at oblique angles of incidence, Applied Optics 45: 1392-1396.

9. Chopra L, Major S, Panday DK (1983) Thin Solid Films 1021
10. Khan ZR, Khan MS, Zulfequar M, Khan MS (2011) Optical and Structural Properties of ZnO Thin Films Fabricated by Sol-Gel Method", Scientific Research, Materials Sciences and Applications 2: 340-345. 